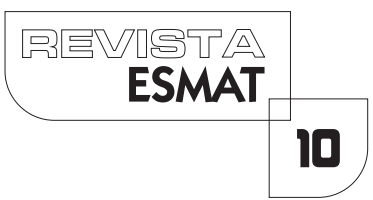

\title{
A RESPONSABILIDADE CIVIL DO ESTADO PELA MOROSIDADE NA EFETIVA PRESTAÇÃO DA TUTELA JURISDICIONAL
}

Isa Omena Machado de Freitas

Especialista em Direito Privado pela Universidade Gama Filho, em Direito Civil e Processo Civil pelo Instituto Tocantinense de Pós-Graduação e em Gerontologia com ênfase em Gerontologia Jurídica pela Universidade Federal do Tocantins. Professora da Faculdade de Ciências Jurídicas de Paraíso do Tocantins (FCJP).

Rosemary Ferreira Santos

Bacharel em Direito pela Faculdade de Ciências Jurídicas de Paraíso do Tocantins (FCJP). Experiência na área de Direito, com ênfase em Direito pelo Escritório J. P. Advocacia. Trabalha no Núcleo de Práticas Jurídicas da Faculdade de Ciências Jurídicas de Paraíso do Tocantins (FCJP).

\section{RESUMO}

Na contemporaneidade, a busca por solução de conflitos sociais tem exigido dos poderes constituídos mais atenção para a estruturação do poder judiciário. A necessidade de celeridade processual é incessante, pautada na dignidade da pessoa e nos princípios universais de direitos humanos. A jurisdição célere é uma das formas de efetivar o acesso à justiça, e a demanda, ao ser levada ao Estado-Juiz, passa a delegar incumbência a este de dizer o direito com a maior brevidade, sob pena de causar danos aos jurisdicionados, pois a celeridade processual também é um direito fundamental, que exige do poder judiciário a sua efetividade de forma célere e eficiente.

PALAVRAS-CHAVE: Morosidade. Responsabilidade civil. Direitos fundamentais. Celeridade processual. Omissão específica.

\section{ABSTRACT}

In contemporary times the search for social conflict resolution has demanded of the constituted powers more attention to the structure of the judiciary. The need for promptness is relentless, based on human dignity and the universal principles of human 
rights. The swift jurisdiction is one way to accomplish the access to justice and demand, to be brought to the State Judge, delegates this task to say the right as soon as possible, otherwise cause damage to the jurisdictional because speed of the procedure is also a fundamental right which requires the judiciary to its effectiveness swiftly and efficiently.

KEYWORDS: Slowness. Civil responsability. Fundamental rights. Speedy trial. Specific omission.

\section{IINTRODUÇÃO}

Antes da necessidade do homem pela acumulação de riquezas, havia o interesse tribal que se materializava pela ordem e pela atividade coletiva. Ao passar do tempo, os hábitos foram se modificando e exigindo do grupo a individualização das atividades. Surge aí o interesse individual que posteriormente se caracteriza pela acumulação de bens, comumente chamados de riquezas.

Com isso, os descontentamentos também passaram a fazer parte no âmbito tribal, pois certas atividades ou acumulações de bens satisfaziam alguns e outros ficavam descontentes. Quando insatisfeito, o membro da tribo interpelava o outro com o apoio dos demais membros. A isso se dava a nomenclatura de vingança coletiva, ao passo que, posteriormente, o próprio membro da tribo buscava sanar suas insatisfações, quando a vingança passou a ser privada. Nesse contexto surgiram os institutos da autodefesa e da autotutela.

Posteriormente surge o Estado, atraindo a prerrogativa de mediar controvérsias, nem a tribo nem o indivíduo podiam forçar a satisfação de seus pretensos direitos sem antes requerer a um membro do Estado, a fim de que este, mediante a imparcialidade no caso concreto, dissesse quem tinha razão no que afirmava.

A responsabilidade civil surge dessas necessidades de reaver as perdas que um membro da sociedade provoca no outro, sendo que ao Estado cabe implantar os meios para essa satisfação jurisdicional, haja vista ser essa a expectativa do lesado, ou seja, a de que a reparação justa se alcançará com a restituição do patrimônio violado ao status quo anterior ao evento danoso. Para tanto, o autor da demanda espera uma resposta rápida da jurisdição que deve ser instituída pelo Estado, como forma de efetivar os princípios constitucionais da inafastabilidade da jurisdição e da razoável duração do processo, bem como da celeridade processual.

O presente trabalho se justifica pela sua relevância temática, pela análise do sistema de responsabilidade civil do Estado e de seu cunho social. Ademais, pauta-se na obrigação positiva de o Estado prestar a jurisdição, tendo em vista sua insurgência como titular do direito de coerção judicial. 
Desta feita, a omissão é um dos fatores que causa dano a outrem e, por isso, requer reparação pela falta da providência necessária para evitar o evento lesivo, tornando-se questão de ordem pública e social, o que também justifica este trabalho. Portanto, a falta ou deficiência na prestação jurisdicional, como a morosidade ou a ineficiência, remontam o necessário estudo.

Deve-se tomar como relevante, para o presente estudo, a questão da celeridade processual. Essa é uma das formas de se efetivar o princípio da razoável duração do processo que, de tamanha relevância, tomou mais fôlego no ordenamento jurídico brasileiro com a Emenda Constitucional n 45, de 2004. Assim, tem-se que a efetividade material do direito deve estar estritamente associada ao direito processual e constitucional, como forma de mostrar-se mais eficiente à jurisdição no momento de dizer o direito.

A busca pela celeridade processual é incessante, pautada na dignidade da pessoa e nos princípios universais de direitos humanos. A jurisdição célere é uma das formas de efetivar o acesso à justiça, e a demanda, ao ser levada ao Estado-Juiz, passa a ter a incumbência de dizer o direito com a maior brevidade, sob pena de causar danos aos jurisdicionados, pois a celeridade processual também é um direito fundamental, que exige do poder judiciário a sua efetividade.

Por fim, chegou-se à conclusão de que o Estado tem responsabilidade civil pela demora na prestação jurisdicional, cujo fundamento se baseia no dever jurídico de disponibilizar meios adequados à prestação jurisdicional, sem os quais o Estado ficará omisso, passível de indenizar prejuízos comprovados, da qual se extrai a responsabilidade subjetiva na modalidade da omissão específica, pois o Estado tem o dever de implementar a justiça célere e com duração razoável.

\section{DAANÁLISE DA RESPONSABILIDADE CIVILDO ESTADO}

A princípio, a responsabilidade civil é vista em sentido latu sensu - em sentido amplo - aplicável, todavia, quando no caso concreto ocorrer ação ou omissão que concorra para lesar bens tutelados ou direitos de outrem. Nesse sentido, a percepção histórica da responsabilidade civil considera haver essa natureza objetiva ou subjetiva, aferível quando da casuística se extrair a culpa que as caracteriza.

Esse ensinamento pode ser retirado dos verbetes de Diniz (2010), da seguinte forma:

No nosso ordenamento jurídico vigora a regra geral de que o dever ressarcitório pela prática de atos ilícitos decorre da culpa, ou seja, da reprovabilidade ou censurabilidade da conduta do agente. $\bigcirc$ comportamento do agente será reprovado ou censurado quando, ante circunstâncias concretas do caso, se entende que ele poderia ou deveria ter agido de modo diferente. Portanto, o ato 
ilícito qualifica-se pela culpa. Não havendo culpa, não haverá, em regra, qualquer responsabilidade (DINIZ, 20I0, p. 4I).

Assim, a caracterização do elemento culpa faz entender violado o dever jurídico primário contratual ou extracontratual (DINIZ, 20I0), por omissão ou comissão, gerando o dever de indenizar pelos prejuízos suportados à vítima do evento. Culpa essa desnecessária quando incidir a responsabilidade objetiva, sob o manto da presunção de que a ação ou omissão resulta em reparação independentemente da comprovação culposa. Contudo, vinculada à demonstração de que o agente agiu com culpa, ônus probatório da vítima, é necessária a comprovação da responsabilidade subjetiva do agente infrator.

Quanto à obrigação de reparar o dano, Kelsen ( 1998) traz o seguinte ensinamento:

Isto é patente no caso de responsabilidade penal pelo delito de outrem, ou seja, no caso em que a sanção tem o caráter de uma pena. Mas vale dizer o mesmo também para o caso da responsabilidade civil pelo delito de outrem quando a sanção tem o caráter de uma execução civil (KELSEN, 1998, p. 84).

Cinge-se, portanto, o questionamento acerca da responsabilidade civil do Estado quando silente, inerte, omisso quanto a um dever de agir. Nesse patamar, Diniz (20 l 0) corrobora ao explicar que,

No ordenamento jurídico brasileiro [...], a responsabilidade das pessoas jurídicas de direito público funda-se nas suas relações com os administrados, em razão de comportamentos comissivos, caso em que, na teoria do risco, será objetiva [...], e omissivos danosos, hipóteses que será subjetiva, conforme a teoria da culpa fundada na falta de serviço (ato ilícito), e, ainda, nas relações entre Estado e funcionário (DINIZ, 20 I 0, p. 643).

Segundo a autora, se a responsabilidade for por omissão, o Estado responde subjetivamente, ou seja, cabe à vítima demonstrar os elementos subjetivos da culpa. Contudo, no momento de aferir a responsabilidade civil estatal, deve-se observar o órgão emanador do ato e sua função típica e atípica. Esse é o entendimento de Cahali citado por Gonçalves (20|3), segundo o qual:

Como poder autônomo e independente, com estrutura administrativa própria e serviços definidos, o judiciário, pelos seus representantes e funcionários, tem a seu cargo a prática de atos jurisdicionais e a prática de atos não jurisdicionais, ou de caráter meramente administrativos; quanto a estes últimos, os danos causados a terceiro pelos serviços da máquina judiciária sujeitam o Estado à responsabilidade civil segundo a regra constitucional, no que se aproximam dos atos administrativos (GONÇALVES, 20 I3, p. 178- 179). 
Como se observa, a trilha é espinhosa para se chegar à natureza jurídica da responsabilidade civil do Estado, quando este atrasa a fornecer decisão terminativa às demandas postas em litígio. Gonçalves (2013) explica que essa responsabilidade está atrelada (ou vinculada) à responsabilidade civil do juiz, sendo amplo e necessário entender se o ato omissivo juridicamente foi danoso e se houve dolo ou fraude que demonstre ausência de motivos justificáveis a bem do serviço público. Parece que esses seriam alguns dos elementos configuradores da responsabilidade civil subjetiva a se demonstrarem na figura culposa. A esse respeito,

Culpa lato sensu indica o elemento subjetivo da conduta humana, o aspecto intrínseco do comportamento, a questão mais relevante da responsabilidade subjetiva. E assim é porque a realização externa de um fato contrário ao dever jurídico deve corresponder a um ato interno de vontade que faça do agente a causa moral do resultado (CAVALIERI FILHO, 20 I 4, p. 44).

A demora na prestação jurisdicional, que é o contraposto da emanação constitucional da celeridade processual, segundo o artigo $5^{\circ}, \mathrm{LXXVIII}$, entendendo-se como direito fundamental (BRASIL, 1988, online), é uma conduta que pode gerar o dever de indenizar. Da mesma forma, o $\S 1^{\circ}$ do citado artigo determina que os "direitos e garantias fundamentais têm aplicação imediata" (BRASIL, 1988, online). Deve-se ao fato de os direitos fundamentais existirem como mecanismo defensivo para o jurisdicionado, de forma que a demora exacerbada na prestação da justiça põe em risco a segurança jurídica.

Assim, aquele que comete um ato ilícito (ou até mesmo lícito, a depender da atividade desenvolvida) e causa dano a outrem tem o dever jurídico de repará-lo, pois "o indivíduo contra quem é dirigida a consequência do ilícito responde pelo ilícito, é juridicamente responsável por ele" (KELSEN, 1998, p. 84).

Nos ensinamentos de Di Pietro (20 I0), tem-se o seguinte entendimento quanto à natureza jurídica da responsabilidade civil do Estado:

Existe controvérsia a respeito da aplicação ou não do artigo $37, \S 6^{\circ}$, da Constituição às hipóteses de omissão do Poder Público, e a respeito da aplicabilidade, nesse caso, da teoria da responsabilidade objetiva. Segundo alguns, a norma é a mesma para a conduta e a omissão do Poder Público; segundo outros, aplica-se, em caso de omissão, a teoria da responsabilidade subjetiva, na modalidade da teoria da culpa do serviço público (DI PIETRO, 2010, p. 654).

Pereira, citado por Gonçalves (20/3), leciona, no mesmo sentido, que "não é indispensável a verificação da ocorrência de culpa dos juízes e funcionários para que se caracterize a responsabilidade do Estado. Basta que o serviço se revele falho" Pereira, citado por (GONÇALVES, 2013, p. 180). Esse entendimento reforça ainda mais a 
necessidade de ir à procura de descobrir a natureza jurídica da responsabilidade civil do Estado pelo atraso na prestação jurisdicional.

No mesmo ponto de referência, Godoy (2009) defende que, em prol da segurança jurídica, foi concedida ao juiz a liberdade de decidir e que, na condição de magistrado (função típica jurisdicional), tem independência funcional, excetuando-se os casos previstos na legislação que lhes impõe limites, segundo o seguinte magistério:

Nesse passo, releva a consideração de que o juiz, no exercício da jurisdição, e para assegurar a isenção de seu julgamento, a liberdade de decidir, a qual, em última análise, encerra garantia da própria parte, tem sua independência erigida em pilar básico do sistema. Aliás, não por outro motivo se estabeleceram, no art. 95 da Constituição Federal, as prerrogativas da Magistratura, mas, ao mesmo tempo, no parágrafo único, fixaram-se especiais vedações que the são muito próprias.

Essa liberdade de convicção e a independência de seu julgamento implicam um particular sistema de responsabilização civil por atos jurisdicionais que pratiquem, no desempenho de sua atividade precípua (GODOY, 2009, p. 75).

Referido autor ainda perfilha quanto à teoria da irresponsabilidade do Estado que não impede este de ser responsabilizado por ato lesivo do Judiciário, reforçando haver previsão constitucional nesse sentido, de sorte ser o entendimento do Supremo Tribunal Federal. Isso é suficiente à demonstração de que o Estado tem o dever de proporcionar a jurisdição, da forma célere que preceitua a Constituição, e quando não implementada a celeridade processual, sobrevém omissão específica do Estado. Contudo, deve-se tomar em limites a aplicação da teoria do risco administrativo constante do artigo 37, § $6^{\circ}$, da Constituição Federal, assim consignando:

Enfim, diante desses antecedentes, sedimentou-se a orientação de que o Estado possa, sim, responder por atos judiciais. Superou-se a consideração da irresponsabilidade do Estado. Isso mesmo que, de pronto, e especialmente no nível da jurisprudência, não se tenha chegado ao ponto de reconhecê-lo sempre obrigado a indenizar danos decorrentes da atividade judicial. Ou seja, mercê inclusive da incidência à espécie do art. 5०, LXXV, da CF/88, como que a erigir um regime especial, formou-se orientação, particularmente pretoriana, de que 0 Estado responde, mas não de modo indistinto, por isso que naquelas hipóteses, apenas, em que o sistema assim o dispuser. Tal a tese que se consolidou no âmbito da Suprema Corte, remissiva aos casos, também positivados, em que o próprio juiz responde [...] (GODOY, 2009, p. 77).

Nesse sentido, o entendimento atual do Supremo Tribunal Federal e do Superior Tribunal de Justiça é o de que a demora razoável na prestação jurisdicional, desde que não ocorra por culpa exclusiva da parte, bem como se foi analisado o mérito da demanda, não tem o condão de reclamar reparação civil por demora na prestação 
A RESPONSABILIDADE CIVIL DO ESTADO PELA MOROSIDADE NA EFETIVA PRESTAÇÃO DA TUTELA JURISDICIONAL

jurisdicional (ARE 683104 AgR/PA; AgRg no AREsp 499464/PE). Da mesma forma, há o verbete da Súmula 106 do Superior Tribunal de Justiça trazendo o posicionamento no sentido de que "proposta a ação no prazo fixado para o seu exercício, a demora na citação, por motivos inerentes ao mecanismo da Justiça, não justifica o acolhimento da arguição de prescrição ou decadência" (BRASIL, 1994, p. 13.885). Esse entendimento também é do Tribunal Regional Federal da Primeira Região, in verbis:

CONSTITUCIONAL EADMINISTRATIVO. DANOS MORAIS. DEMORANA PRESTAÇÃO JURISDICIONAL. RESPONSABILIDADE CIVIL OBJETIVA DO ESTADO. ATOSDO PODERJUDICIÁRIO.

I - A orientação jurisprudencial já consolidada no âmbito de nossos tribunais é no sentido de que, em se tratando de responsabilidade objetiva (CF, art. $37, \S 6^{\circ}$ ), o Estado somente responde por danos decorrentes da prestação jurisdicional em hipóteses expressamente indicadas em lei, quais sejam: a) erro judiciário em condenação penal (CF, art. $\left.5^{\circ}, \mathrm{LXXV}\right)$; b) quando o condenado ficar preso além do tempo fixado na sentença (CF, art. $\left.5^{\circ}, \mathrm{LXXV}\right)$; e c) nas hipóteses do art. 133, do CPC (quando o magistrado no exercício de suas funções agir com dolo ou fraude ou recusar, omitir ou retardar, sem justo motivo, providência que deve ordenar de ofício, a requerimento da parte), inocorrentes, no caso concreto (BRASIL, 2012, p. OI).

Destarte, esses primeiros requisitos são autorizativos à aplicação da responsabilidade objetiva do Estado, na modalidade da teoria do risco administrativo (artigo 37, § 6०, da Constituição Federal), vedada, como visto no ementário antecedente, quando da função típica da judicatura. No entanto, percebe-se que, demonstrada a culpa do órgão ou autoridade pelos atos ilícitos, como elencados acima, tem-se a responsabilidade subjetiva do Estado, seja pela ação ou omissão que acarrete prejuízo a terceiros.

Conforme os ensinamentos de Gonçalves (20ll), outro ponto relevante na aferição da responsabilidade civil é a distinção entre ato e fato. Parece que o primeiro tem íntima relação com um agir humano ou conduta capaz de suscitar repercussão jurídica por ação ou omissão. $\bigcirc$ segundo seria o mecanismo, o meio, a forma de se alcançar o ato. $O$ ponto em comum é que ambos podem gerar a obrigação de reparar o dano.

No caso da responsabilidade civil subjetiva, é importante ressaltar e analisar os elementos que a configura, quais sejam: a ação ou omissão (conduta), o dano, o nexo de causalidade e a culpa. Esta será analisada em sentido lato sensu (amplo).

A ação ou omissão é a conduta humana que se manifesta por meio de atos que, por sua vez, são praticados por meio de fatos jurídicos, violando um dever de observância ou a disposição normativa, ou até mesmo um contrato. A obrigação de reparar pode não ser havida apenas pela ação ou omissão de atos próprios, mas estes podem resultar de atos de terceiros vinculados a outrem. Nesse caso, "a responsabilidade por ato de 
terceiro ocorre quando uma pessoa fica sujeita a responder por dano causado a outrem não por ato próprio, mas por ato de alguém que está, de um modo ou de outro, sob a sujeição daquele" (RODRIGUES, 2003, p. I 5).

O dano é o produto resultante da conduta humana por uma ação ou omissão. $\bigcirc$ dano é a materialização do sofrimento da vítima do evento. Portanto, "o ato ilícito só repercute na órbita do direito civil se causar prejuízo a alguém" (RODRIGUES, 2003, p. 18). Já o nexo de causalidade é um elo entre o ato lesivo e o dano. Este deve, necessariamente, ser atrelado à causa geradora do ilícito danoso. Sem isso, a responsabilidade civil ficará prejudicada.

De outro modo, a culpa é o marco divisor entre a responsabilidade objetiva e a subjetiva. Segundo Rodrigues (2003), a culpa é o elemento caracterizador da responsabilidade civil subjetiva pela reparação do dano causado.

Para a configuração da responsabilidade civil objetiva, a distinção está exatamente no elemento culpa. Esta estará presente apenas quando da responsabilidade subjetiva, sendo desnecessária a comprovação da culpa na modalidade objetiva. Porém, todos os outros elementos (evento danoso, dano e nexo de causalidade) são necessários tanto na responsabilidade objetiva quanto na subjetiva. Cavalieri Filho (20 I 4) traz a seguinte colaboração:
A inobservância desse dever de cuidado toma a conduta culposa - o que evidencia que a culpa é, na verdade, uma conduta deficiente, quer decorrente de uma deficiência da vontade, quer de inaptidões ou deficiências próprias ou naturais. Exprime um juízo de reprovabilidade sobre a conduta do agente, por ter violado o dever de cuidado quando, em face das circunstancias específicas do caso, devia e podia ter agido de outro modo (CAVALIERI FILHO, 20 I 4, p. 48).

No concernente à responsabilidade, faz-se necessário pontuar a omissão genérica da específica. Ambas geram a prerrogativa de indenizar ou reparar por danos provocados. Contudo, a genérica diz-se daquela omissão que o agente não está obrigado em agir ou se omitir. Em que pese em regra seja a responsabilidade objetiva do Estado, com fundamento no artigo 37, § 6 , da Constituição Federal, de 1988, pela teoria do risco administrativo, no caso de omissão, o Estado terá responsabilidade objetiva apenas no caso de omissão específica. Se for genérica, a responsabilidade civil do Estado deverá ser demonstrada por meio da culpa para poder ter o condão de reparar o dano ao administrado.

Para Cavalieri Filho (20। I), "o artigo 37, § 6 , da Constituição não se refere apenas à atividade comissiva do Estado; pelo contrário, a ação a que alude engloba tanto a conduta comissiva como omissiva" (CAVALIERI FILHO, 20l I, p. 16). Assim se configurará omissão específica quando o Estado estiver na condição e dever de agir para com uma obrigação positiva (garantista), sendo que "a responsabilidade do Estado será subjetiva no caso de omissão genérica e objetiva, no caso de omissão específica, pois aí 
há dever individualizado de agir" (CAVALIERI FILHO, 20 I I , p. I6). Portanto, a natureza jurídica da responsabilidade civil do Estado pela morosidade na prestação jurisdicional deve estar associada à omissão estatal e, por isso, relacionada à omissão genérica ou específica.

Não seria concebível desconsiderar a análise da celeridade processual, pois, de ampla importância para o sistema constitucional da efetividade da prestação jurisdicional, do acesso à justiça, é também um direito fundamental. A celeridade processual que parte dessas premissas é de parâmetros de preservação da dignidade da pessoa e tem influxo direto com as diretrizes de direitos humanos.

\section{CONSIDERAÇÕES FINAIS}

Portanto, o Estado deve ser o garantidor da efetivação dos direitos fundamentais, a incluir a celeridade processual como forma de obedecer aos preceitos constitucionais imediatos desses princípios. A premissa maior da efetivação do direito está no garantismo processual de observância obrigatória do poder estatal.

A responsabilidade civil serve exatamente para suprir esse deslinde de efetivação, forçando os poderes constituídos a proporcionarem os meios e mecanismos condizentes com a necessidade dos demandantes e demandados em processo judicial. Não se concebe que o próprio Estado se furte de uma obrigação e fique ileso de responsabilidade, quando tinha o dever jurídico de impedir que prejuízos maiores fossem provocados à vítima de um evento de afeto ao sistema jurídico.

Por isso que a responsabilidade civil do Estado nos casos de atraso na prestação da tutela jurisdicional deve se pautar pelo crivo da omissão específica, por ser notória a obrigação primária do Estado, tendo de prover o necessário para a prestação da justiça célere e eficiente. Premissas essas de caráter constitucional que buscam proteger os direitos de acesso à justiça, à celeridade processual, e a razoável duração do processo, como forma de efetivação real dos direitos e garantias de afeto à vida social buscada a apaziguamento perante o poder judiciário.

Por isso não se vislumbra que tal responsabilidade se estabeleça pela desproporcional responsabilidade subjetiva que mais tem de exigir do ofendido do que efetivar seus direitos. Assim, deve ser afastada a posição jurisprudencial de responsabilidade subjetiva nas hipóteses de omissão jurisdicional que acarreta demora na prestação jurisdicional, até mesmo considerando que os membros do poder judiciário sejam agentes públicos, não podendo, assim, ser afastada a responsabilidade civil objetiva do Estado em casos de omissão jurisdicional. 


\section{REFERÊNCIAS}

BRASIL. (Constituição 1988). Constituição da República Federativa do Brasil de 1988 . Dis p o n ível e m : $<$ http://www.planalto.gov.br/ccivil_03/constituicao/constituicao.htm>. Acesso em $1^{\circ}$ out. 2014.

. Superior Tribunal de Justiça. AgRg no AREsp 499464 / PE - Agravo Regimental no Agravo em Recurso Especial. Relator Ministro Humberto Martins. Julgamento Em | 8 jun. 20 |4. Órgão Julgador: Segunda Turma. DJe 27 jun. 2014.

. Superior Tribunal de Justiça. Súmula $n^{\circ}$ 106. Proposta a ação no prazo fixado para o seu exercício, a demora na citação, por motivos inerentes ao mecanismo da justiça, não justifica o acolhimento da arguição de prescrição ou decadência. Julgamento em: 26 mai. 1994. Corte Especial. Publicação em 3 jun. 1994.

. Supremo Tribunal Federal. RE 683104 AgR / PA - Agravo regimental no recurso extraordinário com agravo. Relator Ministro Luiz Fux. Julgamento em: I I set. 2012. Órgão Julgador: Primeira Turma. DJe em 25 set. 2012.

. Tribunal Regional Federal da Primeira Região. REO 1999.37.00.005205-2 / MA - Remessa Ex Officio. Relator Desembargador Federal Souza Prudente. Órgão Julgador: Quinta Turma. Julgamento em: I 2 mar. 20 I2. Publicado em 23 mar. 2012.

CAVALIERI FILHO, Sérgio. Programa de responsabilidade civil. I I. ed. São Paulo: Atlas, 2014.

A Responsabilidade Civil Objetiva e Subjetiva do Estado. Revista da EMERJ $\overline{\text { Escola }}$ da Magistratura do Estado do Rio de Janeiro. v. I4, n. 55, pp.10-20, jul./set./201 I.

DI PIETRO, Maria Sylvia Zanella. Direito administrativo. 23. ed. São Paulo: Atlas, 2010.

DINIZ, Maria Helena. Curso de direito civil brasileiro: responsabilidade civil. 24. ed. São Paulo: Saraiva, 2010.

GODOY, Cláudio Luiz Bueno de; MALUF, Carlos Alberto Dabus et al. TAVARES DA SILVA, Regina Beatriz (Coord.). Responsabilidade civil: responsabilidade civil e sua repercussão nos tribunais. 2. ed. São Paulo: Saraiva, 2009. 
A RESPONSABILIDADE CIVIL DO ESTADO PELA MOROSIDADE NA EFETIVA PRESTAÇÃO DA TUTELA JURISDICIONAL

GONÇALVES, Carlos Roberto. Direito civil brasileiro: responsabilidade civil. 8. ed. São Paulo: Saraiva, 2013.

GONÇALVES, Marcus Vinicius Rios. Direito processual civil esquematizado. São Paulo: Saraiva, 20I I.

KELSEN, Hans ( 188 | - | 973). Teoria pura do direito. [tradução João Batista Machado]. 6. ed. São Paulo: Martins Fontes, 1998.

RODRIGUES, Silvio. Direito civil: responsabilidade civil. 20. ed. São Paulo: Saraiva, 2003.

Recebido em: 30/04/2015

Aprovado em: 20/06/2016 
